\title{
INTERSEXUALITY AND THE ENDOCRINE ASPECT OF SEX
}

By Richard Goldschmidt, M.D. (Berl.), New Haven (From the Osborn Zoological Laboratory, Yale University.)

$A$ NSWERING the invitation of the editor for a review of the work on sex-intergrades from the viewpoint of endocrinology, we propose to consider in a sweeping form the aspect of the sex-theory as it appears to the auther, both in conclusion of his own work and from an open--minded consideration of all the work done upon the different aspects of the problem. In doing so, we think it will become clear wherein the endocrine aspect of the problem enters, and what are its possibilities and limitations.* The more recent work upon the sex-problem started from very different viewpoints and used very different methods, the methods of cytology, genetics, teratology, physiology, serology, endocrinology, etc. The result is a vast amount of information which, if viewed critically and without prejudice in favor of any method of working or thinking, allows us, we are convinced, to assign to every single phase of that research a place within a general conception of sex.

\section{I}

The basic problem of sex is the question why a differentiation into two sexes occurs generally in living nature. But this question can not concern us here. We take the fact of the existence of the two sexes for granted. Then the first problem which confronts us is to find what causes normally the distribution of the offspring among two different-often extremely dif-

*A detailed analysis of the problem following the same line of thought as presented here will be given in a book which is ready for publication. 
ferent-types of individuals, males and females. This is the problem of the mechanism of the distribution of sex, a problem which is today as completely solved as it is possible within biology. We know that this mechanism is furnished by the existence of two types of gametes in one sex, namely in the male sex, of flies, grasshoppers, mammals, man, and in the female sex of moths and birds, whereas the opposite sex forms only one type of gametes. We know by hybridization experiments that this corresponds closely to the gametic mechanism, which produces the two parental types in equal numbers, when a homozygous form aa, forming only gametes $a$, is mated to a heterozygous form aA, forming gametes both $\mathrm{A}$ and $\mathrm{a}$, the result of the mating being again $1 / 2$ aa and $1 / 2 \mathrm{aA}$. We know further by the cytological work of the past fifteen years that the sex-chromosomes (or X-chromosomes) are visible cell elements which correspond exactly in their behavior to the necessities of a sexdifferentiator by being present in one sex, the homogametic (XX), in every sex-cell, in the other, the heterogametic sex (XY), in only half of the gametes. We know every phase of the history of these sexchromosomes and their behavior throughout the life cycle of the two sexes, every single fact pointing to the idea that they really are or carry the sex-differentiators. We may even state, without running the risk of exaggeration, that the theory which regards the distribution of the $\mathrm{XX}$ - and $\mathrm{XY}$-combinations to about equal numbers of fertilized eggs as the visible mechanism of sex-distribution, is today so far proven, that the demonstration stands on the level of an experimental proof in physics or chemistry. The main points which justify this conclusion are: 1 . The in- 
numerable morphological studies, which in every case that proved favorable to study, found the facts about the sex-chromosomes in accordance with the theory. 2. The cytological study of cases of abnormal sexdistribution, as in Aphids, Nematodes, Hymenoptera, Rotifers, where the behavior of the sex-chromosome fits completely the expectation, although very different ways lead to the result. 3. The cytological study of forms like the moth, which had been proven by experimental breeding to be heterogametic in the female sex, whereas all the forms in which the chromosome mechanism had been studied exhibited male heterogametia. As expected those forms were proved to form two kinds of eggs in regard to the X-chromosomes. 4. The facts about the relation of parthenogenesis to sex, of twinning and polyembryony and about sex-mosaics (gynandromorphism) which are all perfectly clear under the aspects of the sexchromosome theory, but unaccountable otherwise. 5. The study of sex-linked inheritance, which showed that those characters which go in heredity with the sex distribution-both in male and female heterozygosis-follow exactly the distribution of the sexchromosomes in which they must, therefore, be located. 6. The admirable studies on non-disjunction, which prove that in cases of (visible) abnormal distribution of the sex-chromosomes, all the characters which are known to be sex-linked, show special types of inheritance, which coincide exactly with that abnormal distribution, thus showing beyond a shadow of a doubt their location within the sex-chromosome.

We consider, therefore, in agreement with practically all biologists, whose personal experience in both genetics and cytology give special weight to 
their opinion, that the mechanism of sex-distribution is known. Every further construction within the theory of sex has to be built upon this basis.

\section{II}

The knowledge of the mechanism which distributes in the right way those things which are responsible for the ultimate differentiation of male and female sex might be compared with information about the system of tracks and switches within a railroad station. which direct the trains into their different directions. But this knowledge does not furnish any information about the material, the destiny, the loads, or the moving power of the trains. So the next problem in regard to sex is to find out what is moved by the distributing mechanism and how it brings about the differentiation of one or the other sex. The problem of the mechanism of sex-distribution is followed by the problem of the physiology of sex-differentiation. The answer which is usually given as a solution of this problem is, that the sex-chromosomes carry a Mendelian factor, a sex-differentiator. But this solution is not satisfactory, first, because of being only formal and symbolic and referring the question to another unknown quantity; second, because, when worked out in detail, it leads into difficulties, which long since have convinced many cytologists and geneticists that not only the quality of the sex-factor but the quantity of the X-chromosome-substance must be the decisive fact; third, because we can not get around the fact that both sexes contain the anlagen of either sex, which can make their visible appearance irrespective of the gametic or zygotic constitution of the individual under certain experimental 
conditions. We believe that these difficulties have been overcome now and the way towards a physiological understanding of sex-differentiation been cleared by the work on inter-sexuality.*

\section{III}

In order to make clear the relation of the facts of intersexuality to the mechanism of sex-distribution on one side and to the hormonic aspect of sex-differentiation on the other, one point has to be called first to the attention. We know that, in the animal kingdom at least, two types are found in regard to the differentiation of sex-characters (probably also in other processes of growth and differentiation). The one type present in insects, excludes the participation of endocrine activities of the sex-glands in the process of sex-differentiation. Castration or transplantation and transfusion experiments with gonads, blood, body extracts are without influence upon the differentiation of sex-characters. The decision is irrevocably reached at the moment of fertilization. (1) In the other group, however, including birds and mammals, the differentiation of the sex-characters is linked with the endocrine activities of the sex-glands, exactly as growth and metabolism are linked with other endocrine organs, as is proved by the wellknown results of castration and transplantation. It is clear that it will be easier to derive the basic conceptions from the simpler case of insects. (2)

Our experiments, performed with races of the gipsy-moth, have enabled us to get under perfect ex-

*We have proposed the use of the terms intersexe, intersexual, intersexuality instead of sex-intergrades because the former terms can be used in all scientific languages, whereas the latter must be translated, e. g., Sexuelle Zwischenstufen" in German. 
perimental control the production of intersexuality. (3) By building up definite combinations of races by means of cross breeding, we are able to produce without failure and in the expected numerical relations every single intergrade leading from a normal female to a male or vice versa, the end points, of course, being the complete transformation of a (genetically) would-be female into a male and a wouldbe male into a female. Without going into details, we might point to some steps in the analysis of the phenomenon, which justify the conclusions in regard to the problems of this essay. The normal mechanism of sex-distribution in this moth is that of female heterogametia, fertilization resulting in about equal numbers of male and female offspring. All of the races involved behave perfectly normally in this respect. But whereas certain crosses between different races are also normal, others invariably give an abnormal result: the cross A-female times B-male gives normal offspring, but B-male times A-female gives all males normal, all would-be females intersexual. In other crosses with other races the opposite happens,all males are intersexual, all females normal. It could be shown then that the degree of resulting intersexuality is constant for a given combination; e. $g$. the female of race $A$ will give all normal offspring with a male race $M$; but with the male $N$ all would-be females will be slightly intersexual, exhibiting certain male characters; with the male $O$, all would-be females will be intersexual midway between the two sexes; with the male of race $P$, all would-be females will be high grade intersexuals, almost transformed into males; and with the male race $Q$, only males will be produced, although half of them are genetically 
females. If we breed now another race $B$ as female to all these males a similar series will be produced, but it might reach with the male $O$ the point of complete transformation of all would-be females into males.

These facts and their further genetic analysis show that every individual is able to develop into one sex or the other or any stage between; further that every individual contains all the elements necessary for the development of either sex and its attributes; further that these elements or substances must have a certain quantitative relation to each other in order to secure to one of them the control of development; and that the introduction of quantities in a cross which do not fit the given quantity of the other partner set up the sex-differentiation in favor of the higher quantity. The analytical experiments-proved then that the substances which control male differentiation follow the distribution of the sex-chromosomes and must therefore be considered to be carried by them. Whereas the substances controlling female differentiation are always transmitted maternally, that is, from mother to egg. From this it follows, that the mechanism of distribution of the sex-chromosomes results (in the case of female heterozygosis) in distributing to half of the fertilized eggs twice the quantity of the substance which causes male differentiation as to the other half, whereas the substance for female differentiation is constant in all cases. And as the tide of differentiation can be changed in favor of one sex and in a quantitatively increasing series, without any change in the mechanism of the chromosome-distribution it follows, that irrespective of this constitution the decision lies with the respective ab- 
solute quantities of the two sex-substances; the greater quantity wins more or less completely.

But how can we conceive that the greater quantity acts in determining one sex or an intergrade between the two sexes? A careful analysis of the intersexual individuals has given the clue. In studying the different types of male or female intersexuality, we find that not every organ exhibits a definite type between the two sexes, say all of them half or one third between the characters of the sexes. The grade of intersexuality is, moreover, a statement applying to the condition of the animal as a whole. But the different organs are not alike. One organ is already say completely male, another still female, a third female at the base, male at the end. Now it could be proven that the organs or parts of organs which become first changed towards the opposite sex are the ones which are last in embryonic development and the ones which are transformed only in the last steps of intersexuality are the first differentiated embryologically. For example, the sex gland, which is differentiated very early, is transformed into a gland of the opposite sex only when all the somatic organs are already changed. And it is shown from the complete analysis of such facts, that in case of female intersexuality - the other way in male intersexuality-all organs develop female up to a certain turning point, when suddenly the development proceeds under the aspects of male differentiation. Therefore all organs differentiated when the turning point occurs are female, the ones which differentiate later are male, and the ones differentiated over the entire period start female and end male. Thus the degree of intersexuality is determined by the more or less early position 
of the turning point in development. There we have a time coefficient coordinated with the quantitative differences in the amount of sex-differentiating substances, i. e., these are substances which increase the velocity of a reaction proportional to their quantity. It seems safe therefore to ascribe to them at present the character of enzymes.

'The complete analysis of experimental zygotic intersexuality-zygotic because the result is determined at the moment of fertilization-has taught us then what the mechanism of sex-distribution by means of the sex-chromosomes means physiologically: the adjustment of the relative quantities of male and female enzymes, thus assuring to one the greater velocity of reaction. But there is now a limit to our analysis. We see no means of ascertaining what kind the reaction is which is brought about, or, in the language of chemistry, the velocity of which is influenced by the concentration of the enzymes. But the answer can be given, we believe, by the facts about hormonic intersexuality.

\section{IV}

It is well known to every student of biology and physiology that in the higher vertebrates, at least birds and mammals, the endocrine function of the sex-gland plays an important role in the development of secondary sex-characters. Early castration in mammals prevents the normal development of the visible characters, and results in the assumption even of the male secondary characters by female birds. Successful early transplantation of the heterologous gonad makes either sex assume to a more or less complete degree the characters of the other sex. (4) We might call this already the production of hormonic 
intersexuality, which of course appears only in those organs which are physiologically able to change under the influence of hormones, irrespective of the genetic constitution in regard to sex. But the methods which have to be used exclude a complete experiment in intersexuality, where the entire body, including sex-glands, ducts, etc., must react. Fortunately nature has performed such an experiment for us, as F. R. Lillie's recent analysis of the case of the free-martin has revealed. (5) Among twin calves, cases of normal male and female are very rare. If both are not of the same sex, in most cases a normal male is combined with an abnormal "hermaphroditic" female, the freemartin. It is now proven that this freemartin is a typical case of hormonic intersexuality. Lillie could show that in this-and only in this-case an anastomosis between the blood vessels of the twins occurs, so that the same blood flows through both. In the male partner, the testis, with its interstitial tissue, develops first, when the ovary of the female has not yet reached the stage of endocrine function. So the female comes under the influence of the male hormones, the ovary stops differentiation and all the sex-characters develop further in the male direction. The result is the freemartin, a calf with very much female external sex-organs, almost male sexual ducts and a sex-gland containing sperm tubules but without spermatogenesis.

If we compare now this case of true hormonic intersexuality with the zygotic intersexuality of the moth, we see at once that the "turning point" from which sexual differentiation changed in the latter case corresponds exactly to the moment in the case of the freemartin, when the male hormones are 
poured into the blood of the female. Comparing the facts carefully we feel justified therefore in giving the following answer to our former question: Of what kind is the reaction accelerated by the action of the sex-enzymes with a velocity proportional to their concentration? The reaction is the production of the specific hormones of sexual differentiation. In insects this occurs in every single cell of the body as an irreversible consequence of the combination in fertilization. In the higher vertebrates the reaction becomes more or less centralized within the interstitial tissue of the sex glands.

We have purposely dismissed with a few general words the work on castration and transplantation in birds and mammals in order not to interrupt our general line of argument. But we must now draw attention to the fact that some complication comes in here which is not at present completely understood. We mean the complexity of the action of the hormones of the sex-gland on one side and their relation to the genetic (chromosomal) constitution of the cells upon which they act. We have pointed out that the action of these hormones is required when the sex-characters are to differentiate normally. This fact is proved by the castration experiments in mammals, resulting in the failure of further sexual differentiation, and, furthermore, by the case of the freemartin. But there exists another activity of the hormones of the sexgland, namely the inhibition of the sex-characters of the other sex. This is proved by the cock-feathering of old female birds and the fact that castration in female birds makes them assume the characters of the male sex. And this shows again that in these higher vertebrates sexual differentiation is possible without 
specific hormonic action. The latter point is further proved by the fact that in birds typical bilateral gynandromorphs exist, that is, birds with female characters on one side and male characters on the other side of the body. We know from the study of gynandromorphs in insects that they are produced by an abnormality in the distribution of the chromosomes, resulting in the presence of the female set in one half of the body and the male set in the other half. In these gynandromorphous birds the hormones, whatever they are, must be present everywhere in the body; if they were the exclusively decisive factor, no gynandromorphs would occur. To make the case still more complex, gynandromorphic birds are known with an intricate pattern of male and female characters (7); and finally, others are known which, together with the rhythmical change of sexual plumage during one of the breeding seasons, exhibit in certain feathers a mosaic-like admixture of the characters of the other sex. And finally we have the case of une Sebright-Bantams, fowl where the roosters are normally hen-feathered. But when these roosters are castrated they develop normal cock-feathering! (8) No doubt this short accoint already shows the existence of an immense complexity, which cannot be regarded as easily to be disentangled. But we may state in what manner we think the facts may be brought together. We assume that in birds the genetic situation is the same as it is in insects. From the moment of fertilization, every cell contains the two enzymes of sexual differentiation which, in proportion to the quantity in which each is present, accelerate within every cell the production of the hormones 
of sexual differentiation. But there is one principal physiological difference between the insects and birds: in the former the embryonal and larval development ends with one short period of sexual activity after which the animal dies; in the latter, however, a comparatively long period is necessary before the condition of sexual maturity, which then lasts for several years, is reached. If the conditions were alike in the two cases, then every bird would change its sex during its lifetime, that is, it would become intersexual when the amount of the hormones of the other sex within the cells reached a certain mark. This is, however, prevented by the additional phenomenon of the endocrine production of an inhibitory hormone for the characters of the other sex. This specific endocrine function is based on the presence of a sex-limited or, as we prefer to say, sex-controlled factor, as can be deduced from Morgan's SebrightBantam crosses. Thus we may account, at least in principle, for the cases in birds, although additional hypotheses will be necessary for special cases like the Sebright-Bantams or the rhythmical breedingplumage of some birds.

In mammals, however, a further advance seems to have been made in the direction of centralization of the control of the process of differentiation. Here the production of the hormones of sexual differentiation seems to have been shifted from the individual cells to a special endocrine organ, the interstitial tissue of the sex-glands, - a fact most convincingly shown in the case of the freemartin. Castration alone, therefore, can not induce the development of the other sex-characters; that can be accomplished 
only by the transplantation of heterologous gonads. And gynandromorphism seems to be impossible. Finally we repeat that these views can be regarded as provisional only and that much experimental work is still needed here.

\section{$\mathrm{V}$}

Although no other cases of zygotic and hormonic intersexuality are known, where a complete genetic and embryological analysis was possible, the phenomenon will certainly be produced in many other cases. Collectors of insects have often described freaks, which probably are intersexual individuals (not to be confused, however, with gynandromorphs, which are a very different thing); and at least one instance is known where some of the steps produced in our experiments could be duplicated, as in Harrison's crosses of species of the moth Biston. Another instance is found in Daphnids, where Banta (9) found recently a strain throwing constantly intersexuals through many generations, although no experimental control was yet possible. Further the teratology of birds, mammals and man has furnished a considerable number of cases of so-called hermaphroditism and pseudohermaphroditism, many of which are probably cases of hormonic intersexuality, (10) judging from a comparison with the freemartin.*

*Some authors claim that the presence of perverse mating instincts is a type of intersexuality. Halban and others claim it for the case of man, Riddle for cross-bred pigeons, which are supposed to exhibit the perversion more regularly than normal pigeons do, as well as dogs, cows, etc. The possibility of such an explanation can not be denied; but the claim can only be regarded as justified when it is shown that perverted sex-instincts, though permitting also a normal mating, and combined with complete normality of primary and secondary sex-organs, are the starting point or end point of a graduated series of somatic intersexuality. No such evidence is yet available and the behavior of those instincts in intersexual mothsthe only completely analyzed instance-is not in favor of such a view. 
But there are other instances of abnormal sexuality known which we feel justified in considering as further types of intersexuality and which will throw further and important light on the problem. There is first the important case of the Gephyrean worm, Bonellia, as analyzed by Baltzer. (11) Bonellia is well known as the prototype of extreme sexual dimorphism: the female is an animal with a plum-like body to which a very long proboscis is attached, the male is a minute animal of the size of an infusorium, with a rudimentary organization, living within the uterus of the female. If a young larva attaches itself to the proboscis of an adult female and lives there "parasitically" for some time, it develops invariably into a male. Otherwise the larva stays in an indifferent state for some time and then becomes female in the majority of cases. If, however, the experimenter interrupts the "parasitic" stage at different times, individuals develop with different mixtures of male and female characters, that is, intersexual individuals. But there are a few more details which are important for the interpretation of the case. Among the larvae which develop into females, the ones which are late in development, form first sperm, before they become female. Further, a short stage in the parasitic condition accelerates development though it might be female. Then the combination of male and female organs in the intersexes is not orderless, but it seems that the stage of differentiation at the moment of the "turning point" (the interruption of parasitic life) determines the combination. Here we see at once a parallel to the other cases of intersexuality, which suggests the following interpretation: If we wanted to make a decisive experimentum crucis in 
regard to the theory of the quantitatively regulated sex-enzymes, it would be, to find a method which accelerates or retards the velocity of growth and differentiation of the individual without influencing the velocity of reaction of the sex-enzyme. Such a method would enable us to force the processes of differentiation in to the time when the male or female hormones are set free and therefore to make any individual as intersexual as we like. It seems that Bonellia performs this experiment, furnishing the acting substance by the secretion of the proboscis. The interpretation of the case would be, therefore: In the fertilized eggs of Bonellia, which probably are genetically alike, the relation between the velocity of reaction of the sex-enzymes and the velocity of embryonic differentiation is such that a very slow rate of differentiation is confronted with a system of sexenzymes possessing a high concentration of the male and a low concentration of the female enzyme. In normal development, the time of differentiation of most organs lies beyond the point of the late production of female hormones and the animal is therefore female. The function of the secretion of the proboscis is an acceleration of the rate of differentiation, just as, for example, the hormones of the thyroid act upon the metamorphosis of the frog; differentiation then falls within the time of action of male hormones, the female hormones not yet being present at all. And an incomplete acceleration of the rate of differentiation produces intersexuality, i. e., differentiation first under male then under female hormonic conditions. We might therefore call this type intersexuality by activation. The secretion of the proboscis, activating the rate of differentiation, might be regarded as hor- 
monic (although exocrinic) just as the similar action of the thyroidea. It need hardly be added that this hormonic function has nothing to do with the sexhormones.

Another phenomenon should at least be mentioned in this connection,- the so-called protandric hermaphroditism of parasitic crustacea and certain molluscs. In the case of crustacea the simplest typemany others exist-is that the individual develops as a male and later, after having fulfilled as such his functions, begins a parasitic life and is transformed into a female. (12) Gould (13) has described a very similar case in the mollusc Crepidula plana, although no parasitism is here concerned. His experiments, however, show that the development of the male phase of an individual is induced by the presence of larger individuals of either sex. Even female individuals may develop male organs to a certain extent under such circumstances. A similarity is certainly exhibited here to the case of Bonellia, although the details are not so clear.

VI

There is another case of intersexuality which has to be regarded as a special case of zygotic intersexuality. This is the case of the frog, as analyzed by $R$. Hertwig and his students. (14) Here it is possible to produce by certain combinations of races (some races exhibit the same phenomenon in nature) animals which have first an ovary which is gradually changed into a testis during development. We refrain from reporting the complicated details of the important work, as there is no other endocrine aspect of this case of "transitory intersexuality" than the one common to all cases of zygotic intersexuality. 
But another type of intersexuality can not be passed by, the intersexuality as consequence of parasitic castration, because it has been used as a starting point of attack against the hormonic interpretation of sex. (15) The male crab Inachus, if parasited by Sacculina assumes secondary sex-characters of a female and even eggs are formed within the testis. This is, of course, male intersexuality. But the parasited female does not change correspondingly. G. Smith, who analyzed this case, sees the cause of this change of the male towards femaleness in the influence of the parasite upon the fat-metabolism of the host, the metabolism assuming the female type. $\mathrm{He}$ doubts, therefore, an endocrine influence upon sexdifferentiation and adheres to a theory of metabolic stimulation. The parasite as well as the presence of the ovary push the metabolism in the direction of fat-production, as can be demonstrated. Fat constitutes the nutritive material for the eggs and therefore the male sex-cells in the parasited animal grow into eggs.

The last conclusion can be disproved by some facts from our experiments in intersexuality. The normal female caterpillar stores vast amounts of fat, which are used in building up the eggs during pupal life. If now female intersexuality is of such a type that the turning point coincides about with the time of pupation the animal has the large abdomen of the female with all its nutritive material. But then male differentiation begins and no eggs develop in the ovary, which does not grow beyond the larval stage. The hatching intersexual female then possesses the large female abdomen filled with blood rich in fat which could nevertheless not induce the young eggs 
to grow and fill out the abdomen; the presence of the male hormones after the turning point preventing it.

We further fail to see how the facts about parasitic castration could be used against the endocrine aspect of sex-differentiation. A different type of metabolism in regard to the sexes is well known for many classes of animals, even a different protein specificity, as shown by precipitin reactions. There is no reason for putting this difference upon another level than that of other sex-characters, but for the assumption that the hormones of sexual differentiation act upon the morphogenetic processes by the intermediary of a metabolic change. In view of the fact that all endocrine substances including those of the sex-glands, act in some way upon the general metabolism, such an assumption is certainly justified. And it would be in harmony with other physiological facts, e. g., the striking change of the type of metabolism in flies with the metamorphosis, according to Weinland (16) as compared with the influence of the thyroid on starting metamorphosis in frogs. (17) But this is a problem which concerns every phase of the physiology of development and the question of hormonic participation in the process.

We can hardly pass this metabolic aspect of our problem without referring shortly to views, which, in spite of some points of contact, seem to be in contradiction to the views which we derived from our work. We mean the work of Whitman and Riddle and Riddle on pigeons. (18) Riddle has revived the metabolic view of sex-determination which was held in pre-Mendelian, prechromosomal and prehormonic times. He assumes that the metabolic condition of the egg is responsible for the differentiation of sex. 
The material on which he bases his views is genetic as well as physiological. The main genetic fact is, that from a family-cross of doves only males, and from a generic cross nearly all males are produced. But if reproductive overwork is forced upon these birds the early eggs produce mostly or only males, the later eggs mostly or only females. The chemical study of the eggs showed that their metabolic state or energy-content is correlated with the sex of the future animal in normal reproduction as well as in the above mentioned experimental conditions. Riddle seems therefore to believe that these metabolic conditions of the eggs are the basis of sex and controlling these conditions means the control of sex. In looking over all the facts regarding the mechanism and physiology of sex, we feel unable to agree with such a theory, although realizing the importance of the actual facts. One and the same egg of a Rotifer or a bee can develop into a male or female, the decision lying with parthenogenesis or fertilization; the same egg, however, can develop into a gynandromorph or mosaic of male and female parts of any mixture if fertilization is abnormal (the famous Eugster bees). (19) And nevertheless male and female bees are as different in regard to metabolism as any other animal on record (see Straus). (20) One and the same egg of the gipsy moth develops into a female, an intersexe of any description, or a male, the result depending exclusively upon the genetic constitution of the fertilizing sperm, viz., the sex-chromosomes of the sperm, as can be proven with mathematical certainty. In every case of male heterozygosis the situation is the same and the metabolic differences of the sexes are the consequence of the combination in fer- 
tilization, not the cause. We feel justified, therefore, in rejecting a theory of sex, which makes metabolic differences the cause instead of one of the effects of sex-differentiation. We think, moreover, that the importance of that work on doves lies in another direction.* It might belong to the same category of sexproblems as the overripeness experiments of Pfluger, Thury, Hertwig, etc., as the relation of the visible differences in egg-size of Dinophilus to sex, as the problem of male- and female-producers in Aphids and Hymenoptera; the problem of influencing the chromosomal mechanism of sex-distribution; a problem which is certainly of the greatest cytological, physiological and practical interest.

\section{VII}

We have tried to sketch the theory of sex as we see it, as the result of the different lines of research and our own work, and to assign to the endocrine aspects of the problem the right place within. We can hardly finish this very condensed review without pointing to the possibility of applying the same line of argument to the problem of heredity in general.* (26) There is no logical reason for separating the difference in regard to sex from the other specific differences in living nature. The characters which distinguish sex are of the same order as the characters which separate species, genera, families. They are size and shape, symmetry and subdivision, and all the results of differential growth; they are chemical qualities like pigmentation, and all the phases of metabolism; they are further the specificity of proteins. The

* See also Morgan's remarks in his paper quoted in Bib. 8.

$\dagger$ A detailed presentation of the following views will be published as soon as conditions permit.. 
mechanism of the distribution of the determinants of these characters in the process of heredity is in both cases the same, the distribution by means of the chromosomes. Then, just as the differentiation of sexual characters is influenced by endocrine action, important characters of general organization are influenced by the hormones of thyroid, hypophysis, etc., like growth, correlation of organs, metamorphosis, nervous functions, metabolism and instincts. We feel justified, therefore, in applying the same conceptions to all other processes of heredity which we were able to derive for the case of sex because all the differences occur within the offspring of the same parents. So we conceive of the mechanism and physiology of heredity thus: The fertilized egg furnishes in its protoplasm the chemical material and the physical substratum for the processes of growth and differentiation. The chromosomes furnish the determinants or factors for the specific direction of these processes, which make the offspring similar to the parents. These factors are enzymes, which are not only characteristic in regard to their quality, but which are handed over to the sex-cell in very exact quantities or concentrations. As the reactions accelerated by these enzymes take place with a velocity in proportion to their concentration, a very subtle mechanism is given for the production of definite reactions with a different velocity, thus assuring the always returning rhythm of differentiation. As only certain products of reaction will be influenced by the next working enzyme, localization is possible in addition to rhythm. And the reaction accelerated by the enzymes of heredity to a definite velocity, is the formation of hormones, directing growth, metabo- 
lism and differentiation, similar in their action to the known hormones of the thyroid, hypophysis, etc. Thus the entire problem of heredity assumes at a certain point an endocrine aspect.

\section{REFERENCES}

1. See Meisenheimer, I. Experimentelle Studien zur Somaund Geschlechtsdifferenzierung. Jena, 1909.

Kopec; Untersuchungen über Castration und Transplantation bei Schmetterlingen. Arch. Entwicklgsmech. 33, 1911.

2. See Harms, W. Experimentelle Untersuchungen über die ininere Sekretion der Keimdrüsen. Jena, 1914.

Tandler, E., and Grosz, S. Die biologischen Grundlagen der secundären Geschlechscharaktere. Berlin, 1913.

3. See our publications since 1911. The most recent are: Experimental intersexuality and the sex-problem. Amer. Natur. 50, 1916. A further contribution to the theory of sex. Jour. Exp. Zool. 22, 1917. A monographic account of the entire work will be published as soon as conditions permit.

4. Steinach, E. Willkürliche Umwandlung von Säugetiermännchen, etc. Pflüger"s Arch. 144, 1912 . Feminierung von Männchen und Masculierung von Weibchen. Centralbl. Phys. 22, 1913.

Goodale, H. D. Gonadectomy. Carnegie Inst.. Pub. 243, 1916.

5. Lillie, F. R. The freemartin, etc. Jour. Exp. Zool. 23, 1917.

6. Poll, H. Zur Lehre von den secundären Sexualcharacteren. Sitzber. Ges. naturf. Freunde, Berlin, 1909.

Bond, C. I. On a case of unilateral development of secondary male characters in a pheasant, etc. Jour. of Genetics, 3, 1914.

7. Bateson, W., and Rose Haig Thomas. Note on a pheasant showing abnormal sex-characters. Jour. of Genetics, 6, 1917 .

8. Morgan, Th. H. The theory of the gene. Amer. Natur. 1917.

9. Harrison, T. W. H. On hybrids between moths of the geometrid subfamily Bistoninae. Jour. Genetics III, 1914.

Banta, A. M. Sex intergrades in a species of Crustacea. Proc. Nat. Ac. Sc. 1916.

10. See Neugebauer, F. L. von. Hermaphroditismus beim Menschen. Leipzig, 1908. 
11. Baltzer, T. Die Bestimmung des Geschlechts nebst einer Analyse des Geschlechtsdimorphismus bei Bonellia. Mitt. Zool. St. Neapel 22, 1912.

12. See Smith, G. Crustacea in Cambridge Natural History.

13. Gould, H. N. Studies on sex in the hermaphrodite mollusc Crepidula plana. Jour. Exp. Zool. 23, 1917.

14. See R. Hertwig. Ueber den derzeitigen Stand des Sexualitätsproblems. Biol. Centralbl. 3, 1912.

E. Witschi. Studien über Geschlechtsbestimmung bei Fröschen. Arch. mikr. An. 86, 1915.

15. G. Smith. Rhizocephala. Monogr.. Neapel, No. 29, 1906. Studies in the experimental analysis of sex. Quart. Jour. micr. Sc. V. 50, 57, 59. 1910-13.

16. Weinland, E. Ueber die Stoffumsetzungen während der Metamorphose der Fleischfliege. Ztschr. Biol. 47, 1906.

17. Gudernatsch, F. Feeding experiments on tadpoles. Archiv. f. Entwicklunsmech. 35, 1912.

18. Recent reviews, see : Riddle, O. Sex-control and known correlations in pigeons. Amer. Nat. 50, 1916. The theory of sex, etc. Science, 46, 1917.

19. Boveri, Th. Ueber die Entstehung der Eugsterschen Zwitterbienen. Arch. Entwicklungsmech. 41, 1915.

Mehling, E. Ueber die gynandromorphen Bienen, etc. Verh. Phys. Med. Ges. Würzburg, 43, 1915.

20. Straus, I. Die chemische Zusammensetzung der Arbeitsbienen und Drohnen. Ztschr. Biol. 56, 1911. 